\title{
Effects of temperature and trehalose on foam separation of nisin from the culture broth produced by Lactococcus lactis subspecies lactis W28
}

\author{
Y. Wang, F. Nan, H. Zheng, ${ }^{1}$ and Z. Wu ${ }^{1}$ \\ School of Chemical Engineering \& Technology, Hebei University of Technology, No. 8 Guangrong Road, Hongqiao District, Tianjin, 300130, \\ People's Republic of China
}

\begin{abstract}
Nisin is an antimicrobial peptide, an important biopreservative, and it is produced by certain strains of Lactococcus lactis ssp. lactis. In this paper, a foam separation technique was used for the separation of nisin from its culture broth, and the effects of temperature and trehalose on the performance of foam separation of nisin were studied to increase the enrichment ratio and recovery percentage of nisin and decrease the inactivity percentage of nisin. The results showed that temperature and trehalose significantly affected the performance of foam separation of nisin. Under the optimum conditions of $50^{\circ} \mathrm{C}$ temperature, $150-\mathrm{mL} /$ min air flow rate, 400-mL initial loading liquid volume, and $1-\mathrm{g} / \mathrm{L}$ trehalose concentration, the maximum enrichment ratio, recovery percentage, and the minimum inactivity percentage of nisin reached $23.7,84.1 \%$, and $5.9 \%$, respectively, which were, respectively, 5.04, 0.93, and 1.03 times more than those under the conditions of $20^{\circ} \mathrm{C}$ temperature, $150-\mathrm{mL} / \mathrm{min}$ air flow rate, $400-\mathrm{mL}$ initial loading liquid volume, and no trehalose addition. These results indicated that the change of temperature and the addition of trehalose could improve the performance of foam separation of nisin.
\end{abstract}

Key words: nisin, foam separation, temperature, trehalose

\section{INTRODUCTION}

Nisin is an antimicrobial peptide, and it is produced by certain strains of Lactococcus lactis ssp. lactis (Delves-Broughton et al., 1996; Delves-Broughton, 2005; Cao et al., 2007; Jozala et al., 2008; Trmčić et al., 2011). Nisin can intensely inhibit the growth of a wide range of gram-positive microorganisms, which are seriously harmful to foods and it can also inhibit

Received May 10, 2012.

Accepted June 21, 2012.

${ }^{1}$ Corresponding authors: forzhenghuijie@126.com and zhaoliangwu @163.com the growth of Salmonella or some other gram-negative microorganisms by combing EDTA. In addition, nisin is nontoxic to humans. Therefore, nisin is widely used in dairy products, plant protein foods, canned foods, and meat products as a natural preservative in many countries and regions around the world (Cheeseman and Berridge, 1957; Liu and Hansen, 1990; Jung et al., 1992; Roberts et al., 1992; de Vos et al., 1993; Cheigh et al., 2004; Trmčić et al., 2011).

Nisin is produced by liquid culture using strains of Lactococcus lactis ssp. lactis coupled with downstream purification (Cheigh et al., 2004). The main separation methods of nisin reported in the literature are organic solvent extraction (de Arauz et al., 2009), cell adsorption (Yang et al., 1992; Van't Hul and Gibbons, 1996), membrane separation (Daoudi et al., 2001), salting (Daoudi et al., 2001), and other adsorption methods (Coventry et al., 1996; Cheigh et al., 2004). These separation methods have the drawbacks of high cost, complicated operation steps, and serious pollution (Parente and Ricciardi, 1999), which have restricted the widespread application of nisin. Therefore, it is necessary to develop a new separation technology with low cost, simple operation, and no pollution.

Foam separation technology has the advantages of simple equipment, low investment, low energy consumption, and environmental compatibility (Pilon et al. 2002). Early in the 20th century, it had been applied in the metallurgy industry and environmental engineering. During recent years, more attention has been paid to the application of biochemical engineering, particularly the separation of proteins. Foam separation technology uses bubbles as the media and concentrates surfactants on the basis of their adsorption properties on the gasliquid interface due to their hydrophobicity. Sarachat et al. (2010) studied the concentration of a rhamnolipid biosurfactant produced by Pseudomonas aeruginosa SP4 using foam separation and they obtained good separation efficiency of recovery percentage (97\%) of the biosurfactant and enrichment ratio (4) of the biosurfactant. Vanhoute et al. (2008) studied the advancement of foam separation of bioactive peptides and found that a peptidic fraction $(3,500-7,000 \mathrm{Da})$ having 
antimicrobial activity with a $5 \%$ extraction yield could be separated from the $3 \%$ degree of hydrolysis. Hirsch (1950) suggested that foam separation could be used for the separation of nisin, which is also a biosurfactant. Wu et al. (2009) have been studying the separation of nisin from its broth by foam separation for many years and the results have been applied to industrial production (Guo et al., 2006; Liu et al., 2010; Zhang et al., 2011). Enrichment ratio and recovery percentage are used to describe the performance of foam separation. At present, enrichment ratio and recovery percentage in the industrial production process of nisin separation from its broth by foam separation are 5 and $85 \%$, respectively. However, the performance of foam separation for concentrating nisin from its broth should be further improved, especially enrichment ratio, to reduce the separation cost. So, it is necessary to study how to increase the efficiency, especially enrichment ratio, of foam separation for concentrating nisin from its broth.

The main studied parameters affecting foam separation are air flow rate, liquid loading volume, foam height, surfactant concentration, $\mathrm{pH}$, and bubble size. However, temperature is usually neglected. Kumpabooth et al. (1999) and Qu et al. (2008) researched the effect of temperature on the recovery of SDS by foam separation, but the temperature used only ranged from 10 to $35^{\circ} \mathrm{C}$ and from 20 to $25^{\circ} \mathrm{C}$, respectively. Grieves and Bhattacharyya (1965) studied the effect of temperature on foam separation efficiencies using the system of cationic surfactant EHDA-Br, and they did not study the effect of temperature on foam properties. In addition, only a few researchers have investigated the effect of temperature on foam properties (foaming ability and foam stability; Pradhan et al., 1990; Cócera et al., 2003; Zhang et al., 2008). The effects of temperature on the protein separation from whey wastewater and tea saponin separation using 2-stage foam separation were studied (Jiang et al., 2011; Yan et al., 2011). The results showed that the increase in temperature could significantly affect the increase in enrichment ratio. However, no reports exist about the effects of temperature on foam separation of nisin from its culture broth. Therefore, it is very important to study the effects of temperature on foam separation of nisin from its culture broth.

It is possible for the proteins to be denatured during the process of foam separation (Burapatana et al., 2005). Because nisin is a biologically active peptide, it can be denatured using foam separation. To decrease nisin inactivity caused by foam separation, Zhang et al. (2011) researched the effects of ionic strength on nisin inactivity from its culture broth with the addition of sodium chloride and other salts and the results showed that ionic strength was a parameter affecting nisin inactivity caused by foam separation. So, it should also be noted that inactivity percentage of nisin cannot be ignored in foam separation at high temperature because protein thermal denaturation is a more important parameter that affects the functional properties of the proteins (Bellavia et al., 2011). Guo et al. (2006) had studied nisin thermal stability using the different protective agents and the results showed that trehalose could effectively decrease inactivity of the nisin product, which was heated to $115^{\circ} \mathrm{C}$ for $15 \mathrm{~min}$. Trehalose is an effective protective agent that can preserve the structure and functions of the proteins (Yoshii et al., 2008). Furthermore, trehalose is also an important food additive and it does not affect the quality of the nisin product.

In this paper, nisin culture broth, produced by Lactococcus lactis ssp. lactis W28, was used as a system. The effects of temperature on the properties of the system, including viscosity, surface tension, foaming ability, and foam stability, and the efficiency of foam separation were studied for increasing the enrichment ratio of nisin. Then, the effects of trehalose on the efficiency of foam separation were studied for decreasing the inactivity percentage of nisin. So, a new technology could be developed for not only increasing the enrichment ratio of nisin but also for decreasing the inactivity percentage of nisin and increasing the recovery percentage of nisin using foam separation. Therefore, the application of foam separation technology can be promoted in biological and chemical industries.

\section{MATERIALS AND METHODS}

\section{Bacterial Strains and Media}

The nisin-producing strain (Lactococcus lactis ssp. lactis W28) was provided by Tianjin Kangyi Bioengineering Co. Ltd. (Tianjin, China). The culture medium consisted of $50 \mathrm{~g}$ of corn syrup (liquid), $40 \mathrm{~g}$ of sucrose, $20 \mathrm{~g}$ of $\mathrm{KH}_{2} \mathrm{PO}_{4}, 10 \mathrm{~g}$ of peptone, $10 \mathrm{~g}$ of yeast extract, $2 \mathrm{~g}$ of $\mathrm{NaCl}$, and $0.2 \mathrm{~g}$ of $\mathrm{MgSO}_{4} \cdot 7 \mathrm{H}_{2} \mathrm{O}$ per liter of distilled water and its initial $\mathrm{pH}$ was adjusted to 7.6 by $1 \mathrm{~mol} / \mathrm{L}$ of $\mathrm{NaOH}$. Prior to culture, the inoculums were propagated twice at $30^{\circ} \mathrm{C}$ for $8 \mathrm{~h}$ in the seed medium (initial $\mathrm{pH}$ 6.9), which was composed of $20 \mathrm{~g}$ of $\mathrm{KH}_{2} \mathrm{PO}_{4}, 15 \mathrm{~g}$ of sucrose, $15 \mathrm{~g}$ of peptone, $15 \mathrm{~g}$ of yeast extract, $2 \mathrm{~g}$ of $\mathrm{NaCl}$, and $0.2 \mathrm{~g}$ of $\mathrm{MgSO}_{4} \cdot 7 \mathrm{H}_{2} \mathrm{O}$ per liter of distilled water. The culture technology for the production of nisin was the fed-batch culture, which was detailed by $\mathrm{Wu}$ et al. (2009). Micrococcus flavus NCIB 8166, purchased from the China General Microbiological Culture Collection Center (Beijing, China), 
was used as the indicator strain in the nisin bioactivity assay. It was grown in SI medium (initial $\mathrm{pH}$ 7.2; Wu et al., 2009; $10 \mathrm{~g}$ of agar, $10 \mathrm{~g}$ of Tween-20, $8 \mathrm{~g}$ of tryptone, $5 \mathrm{~g}$ of glucose, $5 \mathrm{~g}$ of $\mathrm{NaCl}, 3 \mathrm{~g}$ of yeats extract, and $2 \mathrm{~g}$ of $\mathrm{Na}_{2} \mathrm{HPO}_{4}$ per L of distilled water). This medium was used in the bioassay of nisin. All media were autoclaved at $121^{\circ} \mathrm{C}$ for $20 \mathrm{~min}$ and stored at $4^{\circ} \mathrm{C}$.

Nisin culture broth was obtained from Tianjin Kangyi Bioengineering Co. Ltd. The titer and $\mathrm{pH}$ of nisin culture broth were $4,200 \mathrm{IU} / \mathrm{mL}$ and 3.0, respectively. All above chemical reagents of analytical grade were purchased from Tianjin Yingtaxigui Chemical Reagent Co. (Tianjin, China).

\section{Instruments}

The instruments used in the experiments were a pH meter (research model pHS-25; Shanghai Leici Instrument Factory, Shanghai, China), electronic balance (model FA1204B; Shanghai Precision Scientific Instruments Co. Ltd., China), a Ross-Miles latherometer (model 2151; Shanghai Jianqiang Glass Instrument Co. Ltd., Shanghai, China), an automatic tensiometer (model JYW-200B; Chengde Experimental Machine Co. Ltd., Chengde, China), an air compressor (model AC0-318; Guangdong Hailea Group Co. Ltd., Guangdong, China), a glass rotameter (model LZB-3WB, 30 300 mL/min; Tianjin Hedongwuhuan Factory, Tianjin China), an ultra thermostat (model 501; Shanghai Experimental Instrument Factory Co. Ltd., Shanghai, China), and an Ubbelodhe viscometer (I.D.3-0.49 mm; Shanghai Sendi Scientific Instrument Co. Ltd., Shanghai, China).

\section{Measurement Methods of Broth Properties (Surface Tension and Viscosity)}

Nisin culture broths of different temperatures were prepared from 20 to $80^{\circ} \mathrm{C}$. The broth properties were characterized by surface tension and viscosity. The surface tension and viscosity of the broths with the different temperature were measured by the automatic tensiometer and the Ubbelodhe viscometer, respectively.

\section{Measurement Methods of Foam Properties (Foaming Ability and Foam Stability)}

Nisin culture broths of different temperature were prepared from 20 to $80^{\circ} \mathrm{C}$. The foam properties of the broths were characterized by the foaming ability and the foam stability, which were measured by the RossMiles latherometer (Carey and Stubenrauch, 2010; Yulin et al., 2010). The foaming ability and the foam stability were described by foam height $(\mathrm{mm})$ and half collapse time $\left(\mathrm{t}_{1 / 2} ; \mathrm{min}\right)$ of the foam phase.

\section{Experimental Process}

Figure 1 shows the experimental apparatus for foam separation. The foam separation column with marked scales was $1,200-\mathrm{mm}$ tall with an i.d. of $40 \mathrm{~mm}$ and it was manufactured from transparent polymethyl methacrylate. The air compressor and the glass rotameter were used to control the flow of the compressed air, which passed through a sintered glass gas distributor of apertures about 40 to $60 \mu \mathrm{m}$ at the bottom of the column. Bubbles formed in the bulk liquid phase when the air passed through the distributor. The column was tightly wound by a silica gel tube. The silica gel tube was connected to the ultra thermostat by which the temperature of the column was adjusted. Foam from the top of the column overflowed into a collection vessel. The process was operated until no foam overflowed from the column. The volume and the titer of the foam concentrate liquid and the residual broth were measured to calculate the enrichment ratio $(E)$, recovery percentage $(R)$, residual percentage $(r)$, and inactivity percentage $(I)$ using Equations 1 to 4 :

$$
\begin{gathered}
E=T_{f} T_{i} ; \\
R=T_{f} V_{f} / T_{i} V_{i} \times 100 \% ; \\
r=T_{r} V_{r} / T_{i} V_{i} \times 100 \% ; \\
I=100 \%-R-r,
\end{gathered}
$$

where $T_{f}, T_{i}$, and $T_{r}$ are the titers of nisin in the foam concentrate broth, the initial broth, and the residual broth, respectively; and $V_{f}, V_{i}$, and $V_{r}$ are the volumes of the foam concentrate liquid, the initial broth, and the residual broth, respectively.

The titer of nisin culture broth $(4,200 \mathrm{IU} / \mathrm{mL})$ could be maintained when the $\mathrm{pH}$ of the broth was 3.0. However, the titer of the broth decreased easily with the increase in $\mathrm{pH}$ (Jozala et al., 2008). Therefore, the $\mathrm{pH}$ of the broth was at 3.0 in the experiments and the effects of $\mathrm{pH}$ on the performances of foam separation of the broth were not studied. All of the above experiments were performed in triplicate.

\section{Measurement Method of Nisin Titer}

The agar diffusion method was used to measure the titer of nisin, and it is a bioassay used for the quantification of nisin by measuring the response of nisin 


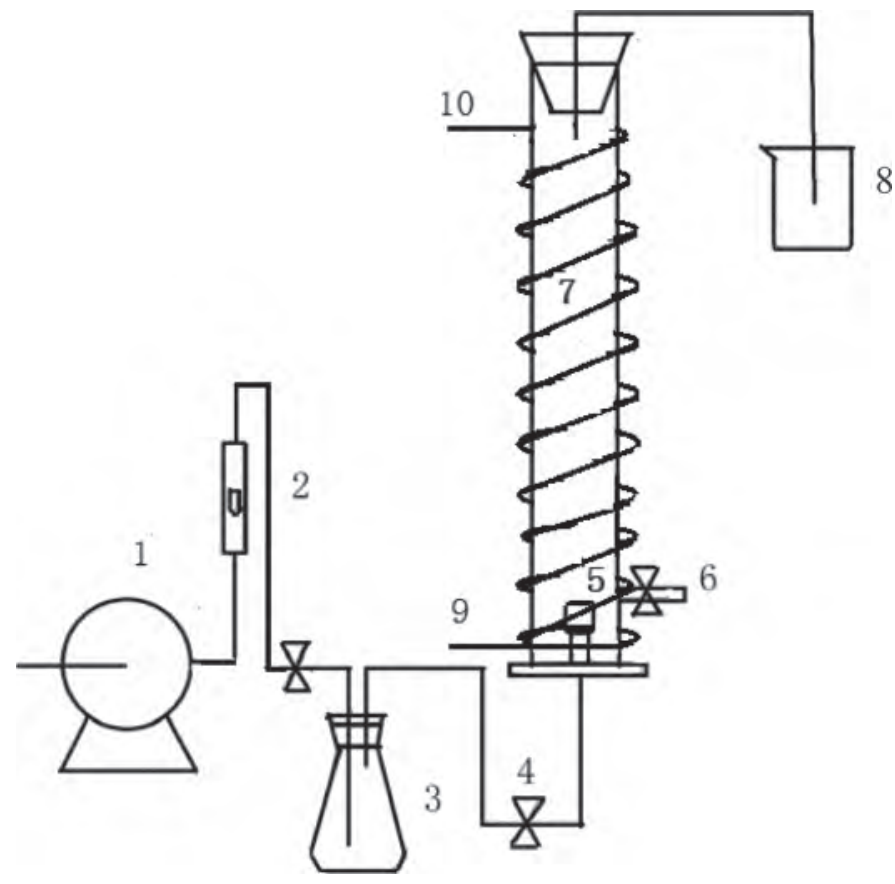

Figure 1. Experimental apparatus for foam separation. $1=$ air compressor; $2=$ rotameter; $3=$ alkali bottle; $4=$ valve; $5=$ distributor; $6=$ outlet; $7=$ foam separation column; $8=$ foam collector; $9=$ water inlet; $10=$ water outlet.

introduced into growth media of test organisms (Wu et al., 2009).

\section{RESULTS AND DISCUSSION}

\section{Effect of Temperature on the Broth Properties and the Foam Properties of Nisin Culture Broth}

Effect of Temperature on the Broth Properties of Nisin Culture Broth. The effect of temperature on viscosity and surface tension of nisin culture broth is shown in Figure 2a. The viscosity of the nisin culture broth decreased significantly with the increase in temperature from 20 to $80^{\circ} \mathrm{C}$. The increase in temperature led to the expansion of the liquid volume and the increase of the distance between molecules. Therefore, intermolecular forces were weakened. Furthermore, the increase in temperature intensified the molecular motion of nisin and some of the micella formed by nisin molecules were destroyed. So, the viscosity of nisin culture broth decreased significantly with the increase of temperature.

The surface tension of the nisin culture broth decreased significantly with the increase in temperature. The increase in temperature led to the increase in the saturated vapor pressure and the increase in water percentage in the air phase. Furthermore, the increase in temperature intensified the molecular motion of nisin and the intermolecular forces were weakened. So, it was more difficult for nisin molecules to form the micelle, resulting in a decrease in the molecule diffusion resistance. Then, it was much easier for nisin molecules to adsorb onto the gas-liquid interface. Therefore, the surface tension of the nisin culture broth decreased significantly with the increase in temperature.

Effect of Temperature on the Foam Properties of Nisin Culture Broth. The effect of temperature on foaming ability and foam stability of the nisin culture broth is shown in Figure 2b. The foaming ability of the nisin culture broth decreased with the increase in temperature. The increase in temperature led to the decrease in viscosity of the nisin culture broth. As a

a)

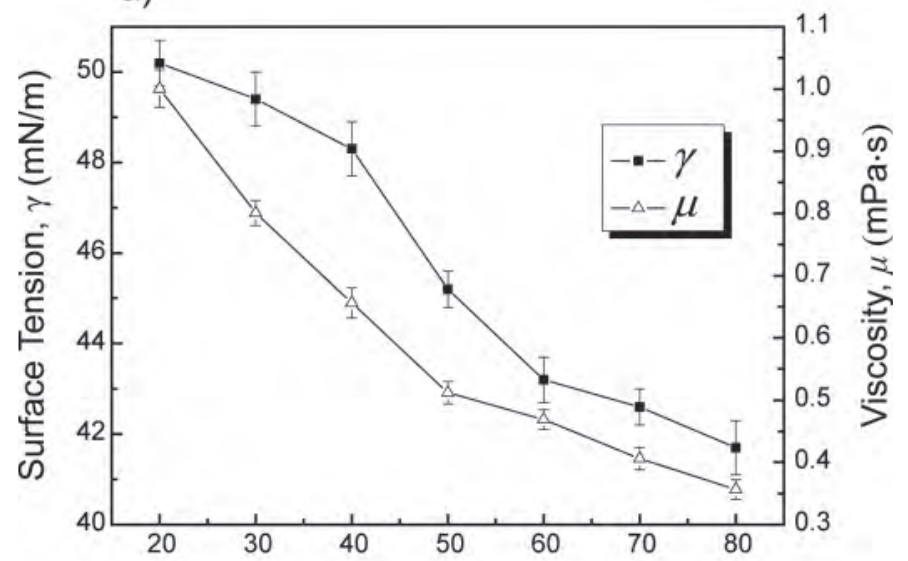

b)

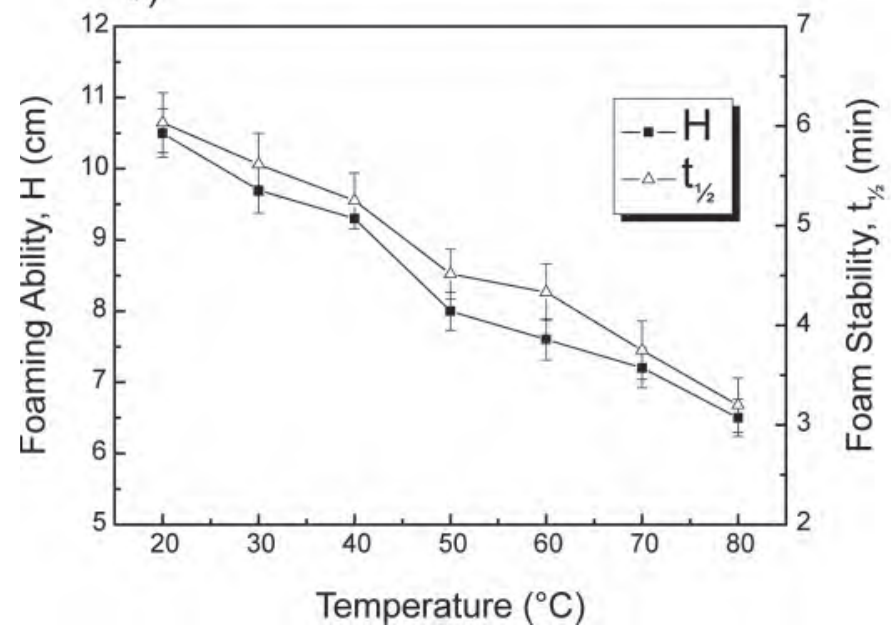

Figure 2. (a) Effect of temperature on the viscosity and surface tension of nisin fermentation broth. (b) Effect of temperature on the foaming ability and foam stability of nisin fermentation broth. The experimental data are presented in terms of arithmetic averages of at least 3 replicates, and the standard deviations are indicated by error bars. 
result, it was hard to form enough thick liquid film, resulting in an increase in bubble coalescence. Therefore, the foam height was smaller when the temperature was higher.

The foam stability of the nisin culture broth decreased with the increase in temperature. The resistance of foam drainage decreased due to the decrease in viscosity of the nisin culture broth with the increase in temperature and the liquid film became thinner. Furthermore, the liquid film of the upper foam always protruded upward, which made the film sensitive to evaporation and the increase in temperature led to a decrease in the relative humidity, so the evaporation of the liquid film accelerated ( $\mathrm{Li}$ et al., 2010). As a result, the thickness of the liquid film became thinner and the foam stability of the nisin culture broth decreased.

\section{Effect of Temperature on the Foam Separation Efficiency of Nisin}

Effect of Temperature on the Enrichment Ratio and Recovery Percentage of Nisin. The effects of temperature on the enrichment ratio and recovery percentage of nisin were carried out under the conditions of $150-\mathrm{mL} / \mathrm{min}$ air flow rate and $400-\mathrm{mL}$ initial loading liquid volume. The temperature ranged from 20 to $80^{\circ} \mathrm{C}$. The effects of temperature on the enrichment ratio and recovery percentage of nisin are shown in Figure 3a.

The recovery percentage of nisin decreased with the increase in temperature. The enrichment ratio of nisin increased and then decreased slightly with the increase in temperature from 20 to $50^{\circ} \mathrm{C}$ and from 50 to $80^{\circ} \mathrm{C}$, respectively. The viscosity of nisin culture broth decreased significantly with the increase in temperature from 20 to $50^{\circ} \mathrm{C}$ and the foam drainage was improved. So, the coalescence of the bubbles in the foam phase increased and the foam concentrate liquid volume decreased. Therefore, the enrichment ratio of nisin increased and the recovery percentage of nisin decreased significantly. However, inactivity of nisin occurred in the foam separation process. The effect of inactivity of nisin at the higher temperature was more dominant than the effect of the foam drainage. Therefore, the enrichment ratio of nisin decreased when the temperature was above $50^{\circ} \mathrm{C}$.

Effect of Temperature on the Inactivity Percentage of Nisin. The effect of temperature on the inactivity percentage of nisin was carried out under the same conditions as above. The effect of temperature on inactivity percentage of nisin is shown in Figure 3b.

The inactivity percentage of nisin increased with the increase in temperature. In the foam separation process,
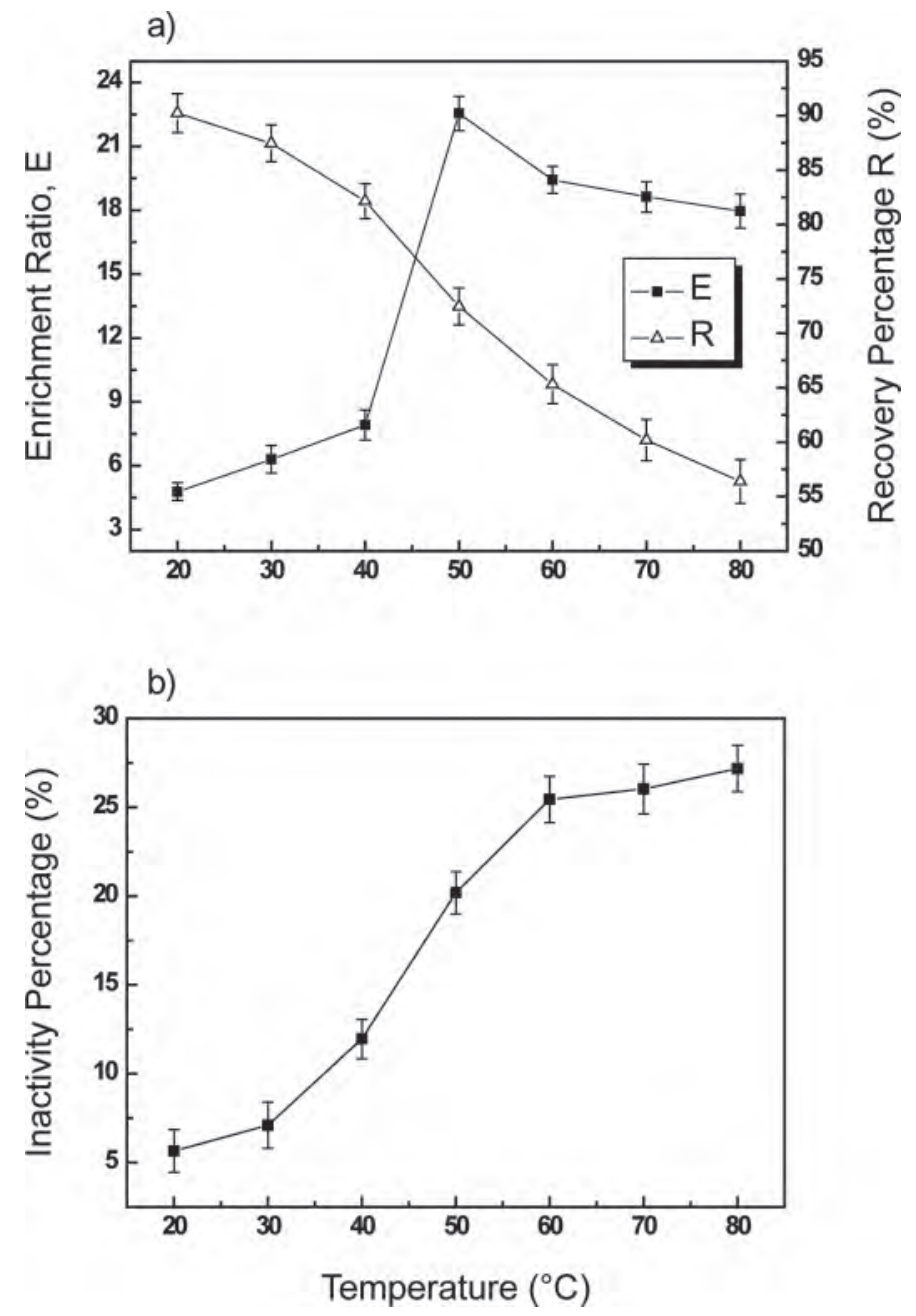

Figure 3. (a) Effect of temperature on the enrichment ratio and recovery percentage of nisin. (b) Effect of temperature on the inactivity percentage of nisin. The experimental data are presented in terms of arithmetic averages of at least 3 replicates, and the standard deviations are indicated by error bars.

many factors, especially the formation, coalescence, and rupture of the bubbles and oxidation, led to the inactivity of biosurfactants, such as enzymes (Liu et al., 1998; Clarkson et al., 1999a,b; Burapatana et al., 2004). The coalescence and rupture of the bubbles in the foam phase and the oxidation of the biosurfactants increased with the increase in temperature and so the inactivity percentage of nisin increased during foam separation. Therefore, the optimal temperature was $50^{\circ} \mathrm{C}$.

\section{Effect of Air Flow Rate on the Enrichment Ratio and Recovery Percentage of Nisin at $50^{\circ} \mathrm{C}$}

The effects of air flow rate on the enrichment ratio and recovery percentage of nisin were carried out under 


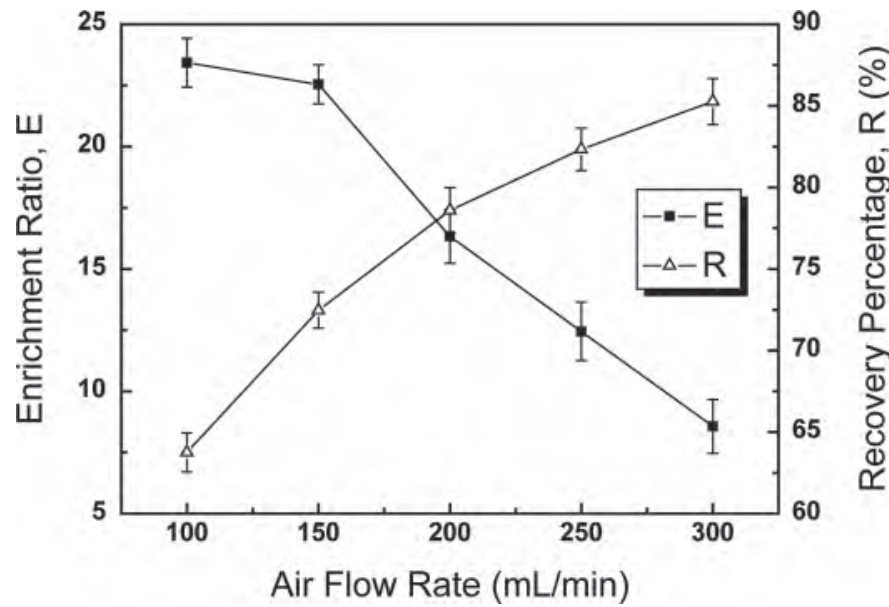

Figure 4. Effect of air flow rate on the enrichment ratio and recovery percentage of nisin at $50^{\circ} \mathrm{C}$ temperature. The experimental data are presented in terms of arithmetic averages of at least 3 replicates, and the standard deviations are indicated by error bars.

the conditions of initial 400-mL loading liquid volume and $50^{\circ} \mathrm{C}$ temperature. The air flow rate ranged from 100 to $300 \mathrm{~mL} / \mathrm{min}$. The effects of air flow rate on the enrichment ratio and recovery percentage of nisin are shown in Figure 4.

An increase in air flow rate increased both the transportation of the bulk liquid into the foam and the biosurfactant adsorption onto the increasing surface area of the bubbles. Therefore, the foam became wetter and the foam concentrate liquid volume was greater, leading to a decrease in the enrichment ratio of nisin. In contrast, at a lower air flow rate, a longer residence time of the bubbles in the rising foam increased the foam drainage, resulting in a dryer foam with a higher nisin concentration in the foam concentrate liquid. So, the larger enrichment ratio of nisin was obtained at the lower gas velocity rate. Therefore, the optimal air flow rate was $150 \mathrm{~mL} / \mathrm{min}$.

\section{Effect of Initial Loading Liquid Volume on the Enrichment Ratio and Recovery Percentage of Nisin at $50^{\circ} \mathrm{C}$}

The effects of initial loading liquid volume on the enrichment ratio and recovery percentage of nisin were carried out under the conditions of $150-\mathrm{mL} / \mathrm{min}$ air flow rate and $50^{\circ} \mathrm{C}$ temperature. The initial loading liquid volume ranged from 300 to $600 \mathrm{~mL}$. The effects of initial loading liquid volume on enrichment ratio and recovery percentage of nisin are shown in Figure 5.

The enrichment ratio of nisin decreased with the increase in initial loading liquid volume, whereas the recovery percentage of nisin increased from with an increase in the initial loading liquid volume from 300 to $400 \mathrm{~mL}$ and then decreased with an increase in the initial loading liquid volume from 400 to $600 \mathrm{~mL}$. The foam height decreased with the increase in initial loading liquid volume, leading to a shorter residence time of bubbles in the foam phase and so the enrichment ratio of nisin decreased. When the initial loading liquid volume was small, the height of the foam phase was large and the increase of the foam height led to a longer foam residence time, which improved foam drainage. But inactivity percentage of nisin increased at high temperature $\left(50^{\circ} \mathrm{C}\right)$ and so the recovery percentage of nisin was small when the initial loading liquid volume was small. So, the largest recovery percentage of nisin was $72.5 \%$ when initial loading liquid volume was 400 $\mathrm{mL}$. Therefore, the optimal initial loading liquid volume was $400 \mathrm{~mL}$.

\section{Effect of Trehalose on Foam Separation Efficiency of Nisin at $50^{\circ} \mathrm{C}$}

Effect of Trehalose on the Inactivity Percentage of Nisin at $50^{\circ} \mathrm{C}$. The results from Figure $3 \mathrm{~b}$ show that inactivity percentage of nisin was as high as $20.2 \%$ at $50^{\circ} \mathrm{C}$ temperature. To decrease the inactivity percentage of nisin, the effects of trehalose on the inactivity percentage of nisin were carried out under the conditions of $50^{\circ} \mathrm{C}$ temperature, $150-\mathrm{mL} / \mathrm{min}$ air flow rate, and $400-\mathrm{mL}$ initial loading liquid volume. The concentration of trehalose ranged from 0 to $2.5 \mathrm{~g} / \mathrm{L}$. The results are shown in Figure 6a.

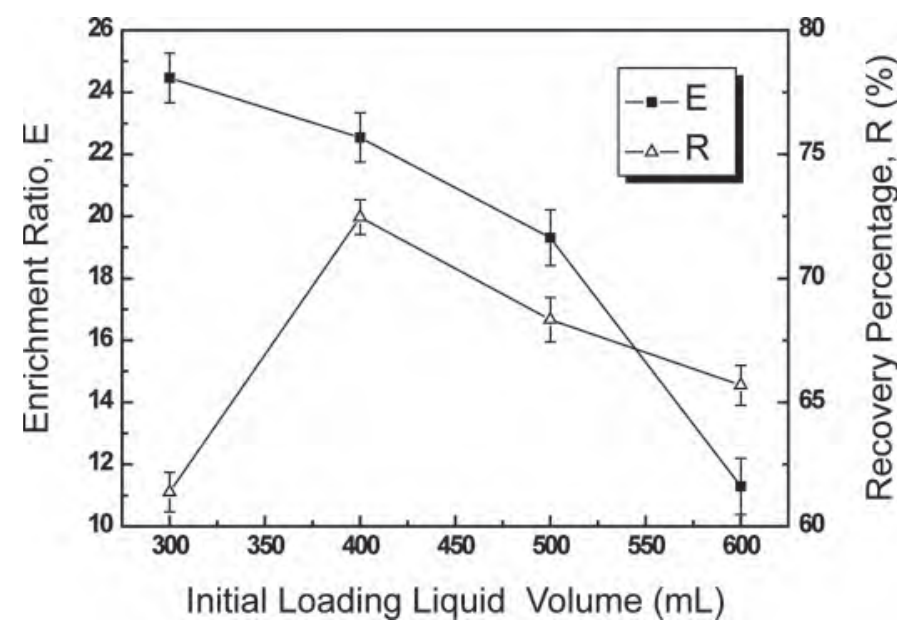

Figure 5. Effect of initial loading liquid volume on the enrichment ratio and recovery percentage of nisin at $50^{\circ} \mathrm{C}$ temperature. The experimental data are presented in terms of arithmetic averages of at least 3 replicates, and the standard deviations are indicated by error bars. 
a)

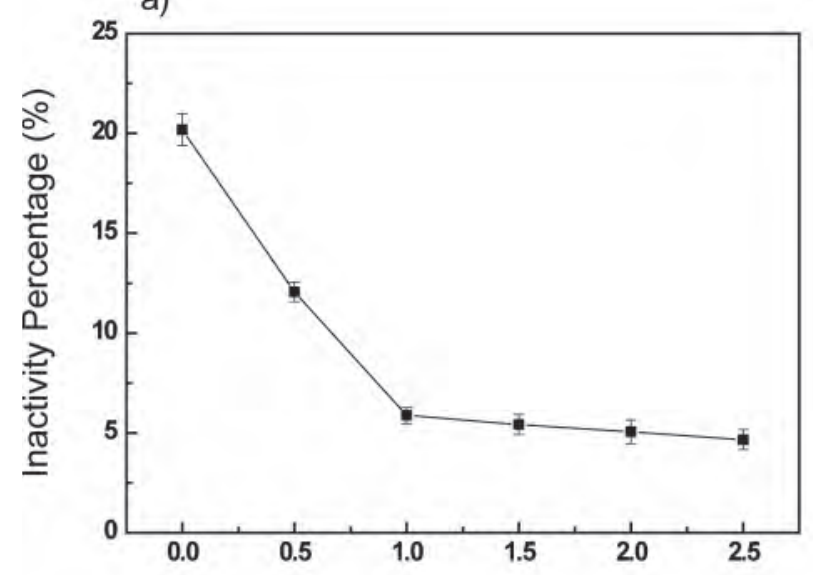

b)

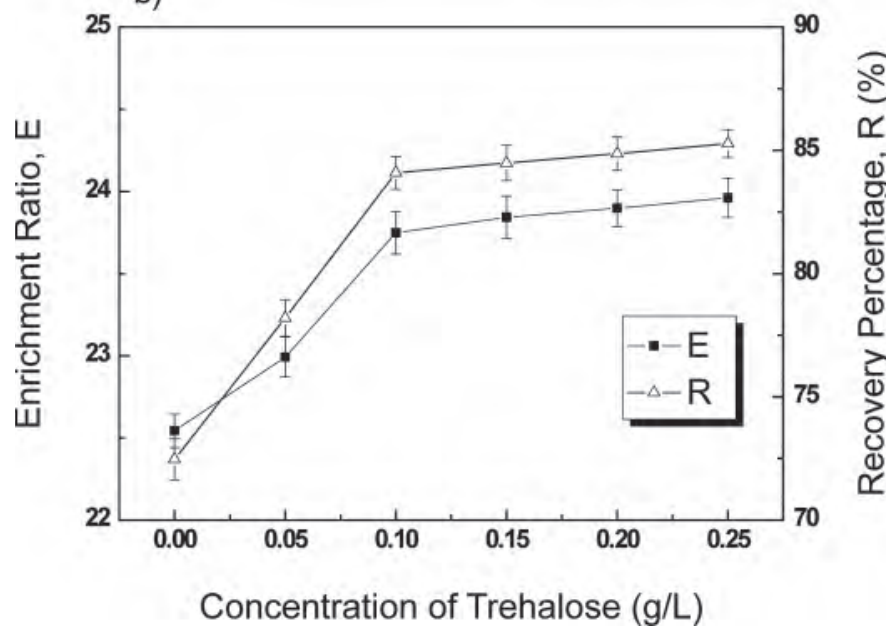

Figure 6. (a) Effect of concentration of trehalose on the inactivity percentage of nisin. (b) Effect of concentration of trehalose on the enrichment ratio and recovery percentage of nisin at $50^{\circ} \mathrm{C}$ temperature. The experimental data are presented in terms of arithmetic averages of at least 3 replicates, and the standard deviations are indicated by error bars.

From Figure 6a, trehalose had an important effect of decreasing the inactivity percentage of nisin during the foam separation process. Trehalose is an exceptional stabilizer of proteins and helps retain the activity of enzymes in solution (Kaushik and Bhat, 2003). Yoshii et al. (2008) studied the retention of the enzymatic activity of alcohol dehydrogenase on spray-drying conditions using trehalose and the results showed that trehalose was an effective protective agent that could preserve the structure and activity of the enzyme. Nisin is an antimicrobial polypeptide characterized by a complex advanced structure and the presence of 4 unusual AA (Gross and Morell, 1971) of which dehydroalanine and $\beta$-methyldehydroalanine were related to intensely inhibiting the growth of a wide range of gram-positive microorganisms. So, trehalose was also an effective protective agent that could preserve the structure and activity of nisin during the foam separation process.

The inactivity percentage of nisin decreased significantly with the increase in trehalose concentration from 0 to $1.0 \mathrm{~g} / \mathrm{L}$. When the titer of nisin culture broth was constant, more nisin molecules were protected at higher trehalose concentration because almost all trehalose molecules played their role at a lower mole ratio of trehalose to nisin. When trehalose concentration was higher than $1.0 \mathrm{~g} / \mathrm{L}$, the decrease in inactivity percentage of nisin became insignificant because it was difficult for some trehalose molecules to play their role at a higher mole ratio of trehalose to nisin. Therefore, the optimal trehalose concentration was $1.0 \mathrm{~g} / \mathrm{L}$.

Effect of Trehalose on the Enrichment Ratio and Recovery Percentage of Nisin at $50^{\circ} \mathrm{C}$. The effects of trehalose on the enrichment ratio and recovery percentage of nisin were carried out under the conditions of $50^{\circ} \mathrm{C}$ temperature, $150-\mathrm{mL} / \mathrm{min}$ air flow rate, and 400-mL initial loading liquid volume. The trehalose concentration ranged from 0 to $2.5 \mathrm{~g} / \mathrm{L}$. The results are shown in Figure 6b.

The results from Figure $6 \mathrm{~b}$ showed that the enrichment ratio and recovery percentage of nisin increased significantly with the increase in trehalose concentration from 0 to $1.0 \mathrm{~g} / \mathrm{L}$ and the increase in the enrichment ratio and recovery percentage of nisin became insignificant when the trehalose concentration was higher than $1.0 \mathrm{~g} / \mathrm{L}$. So, the effects of trehalose on the enrichment ratio and recovery percentage of nisin were consistent with those of trehalose on inactivity percentage. The enrichment ratio and recovery percentage of nisin were 23.7 and $84.1 \%$, respectively, at the optimal trehalose concentration $1.0 \mathrm{~g} / \mathrm{L}$.

\section{CONCLUSIONS}

The present experimental studies showed that temperature and trehalose significantly affected the enrichment ratio, recovery percentage, and inactivity percentage of nisin. The enrichment ratio of nisin increased significantly with the increase in temperature from 20 to $50^{\circ} \mathrm{C}$. The inactivity percentage of nisin decreased significantly with the increase in trehalose concentration from 0 to $1.0 \mathrm{~g} / \mathrm{L}$. Under the optimum conditions of $50^{\circ} \mathrm{C}$ temperature, $150-\mathrm{mL} / \mathrm{min}$ air flow rate, $400-\mathrm{mL}$ initial loading liquid volume, and $1-\mathrm{g} / \mathrm{L}$ concentration of trehalose, the maximum enrichment ratio and recovery percentage and the minimum inactivity percentage of nisin reached $23.7,84.1 \%$, and $5.9 \%$, respectively, which were, respectively, 5.04, 0.93, and 1.03 times more than those under the conditions of 
$20^{\circ} \mathrm{C}$ temperature, $150-\mathrm{mL} / \mathrm{min}$ air flow rate, $400-\mathrm{mL}$ initial loading liquid volume, and no trehalose addition. Therefore, the change in temperature and the addition of trehalose can promote the application of foam separation technology in biological and chemical industries.

\section{ACKNOWLEDGMENTS}

This work was financially supported by the Natural Science Foundation of Hebei Province, China (no. B2011202056).

\section{REFERENCES}

Bellavia, G., S. Giuffrida, G. Cottone, A. Cupane, and L. Cordone. 2011. Protein thermal denaturation and matrix glass transition in different protein-trehalose-water systems. J. Phys. Chem. B 115:6340-6346.

Burapatana, V., A. Prokop, and R. D. Tanner. 2005. A comparison of the activity reduction occurring in two detergent-assisted protein (cellulase and lysozyme) foam fractionation processes. Sep. Sci. Technol. 40:2445-2461.

Burapatana, V., A. Prokop, and R. D. Tanner. 2004. Degeneration of $\beta$-glucosidase activity in a foam fractionation process. Appl. Biochem. Biotechnol. 113-116:619-625.

Cao, L. T., J. Q. Wu, F. Xie, S. H. Hu, and Y. Mo. 2007. Efficacy of nisin in treatment of clinical mastitis in lactating dairy cows. J. Dairy Sci. 90:3980-3985.

Carey, E., and C. Stubenrauch. 2010. Foaming properties of mixtures of a non-ionic $\left(\mathrm{C}_{12} \mathrm{DMPO}\right)$ and an ionic surfactant $\left(\mathrm{C}_{12} \mathrm{TAB}\right)$. J. Colloid Interface Sci. 346:414-423.

Cheeseman, G. C., and N. J. Berridge. 1957. An improved method of preparing nisin. Biochem. J. 65:603-608.

Cheigh, C.-I., M.-C. Kook, S.-B. Kim, Y.-H. Hong, and Y.-R. Pyun. 2004. Simple one-step purification of nisin Z from unclarified culture broth of Lactococcus lactis subsp. lactis A164 using expanded bed ion exchange chromatography. Biotechnol. Lett. 26:13411345 .

Clarkson, J. R., Z. F. Cui, and R. C. Darton. 1999a. Protein denaturation in foam: I. Mechanism study. J. Coll. Interface Sci. 215:323-332

Clarkson, J. R., Z. F. Cui, and R. C. Darton. 1999b. Protein denaturation in foam: II. Surface activity and conformational change. J. Coll. Interface Sci. 215:333-338.

Cócera, M., O. López, J. Estelrich, J. L. Parra, and A. de la Maza. 2003. Influence of the temperature in the adsorption of sodium dodecyl sulfate on phosphatidylcholine liposomes. Chem. Phys. Lipids 124:15-22.

Coventry, M. J., J. B. Gordon, M. Alexander, M. W. Hickey, and J. Wan. 1996. A food-grade process for isolation and partial purification of bacteriocins of lactic acid bacteria that uses diatomite calcium silicate. Appl. Environ. Microbiol. 62:1764-1769.

Daoudi, L., C. Turcotte, C. Lacroix, and I. Fliss. 2001. Production and characterization of anti-nisin Z monoclonal antibodies: Suitability for distinguishing active from inactive forms through a competitive enzyme immunoassay. Appl. Microbiol. Biotechnol. 56:114-119.

de Arauz, L. J., A. F. Jozala, P. G. Mazzola, and T. C. Vessoni Penna. 2009. Nisin biotechnological production and application: A review. Trends Food Sci. Technol. 20:146-154.

de Vos, W. M., J. W. M. Mulders, R. J. Siezen, J. Hugenholtz, and O. P. Kuipers. 1993. Properties of nisin Z and distribution of its gene, nisZ, in Lactococcus lactis. Appl. Environ. Microbiol. 59:213-218.

Delves-Broughton, J. 2005. Nisin as a food preservative. Food Aust. $57: 525-532$.
Delves-Broughton, J., P. Blackburn, R. J. Evans, and J. Hugenholtz. 1996. Applications of the bacteriocin, nisin. Antonie Van Leeuwenhoek 69:193-202.

Grieves, R., and D. Bhattacharyya. 1965. The effect of temperature upon foam fractionation. J. Am. Oil Chem. Soc. 42:174-176.

Gross, E., and J. L. Morell. 1971. Structure of nisin. J. Am. Chem. Soc. 93:4634-4635.

Guo, Y., Z. Wu, Y. Ji, and G. Yu. 2006. The study about the substance of protecting the stability of nisin. Food Res. Develop. 127:200-202.

Hirsch, A. 1950. The assay of the antibiotic nisin. J. Gen. Microbiol. 4:70-83.

Jiang, C., Z. Wu, R. Li, and Q. Liu. 2011. Technology of protein separation from whey wastewater by two-stage foam separation. Biochem. Eng. J. 55:43-48.

Jozala, A. F., A. M. Lopes, P. G. Mazzola, P. O. Magalhães, T. C. Vessoni Penna, and A. Pessoa Jr.. 2008. Liquid-liquid extraction of commercial and biosynthesized nisin by aqueous two-phase micellar systems. Enzyme Microb. Technol. 42:107-112.

Jung, D. S., F. W. Bodyfelt, and M. A. Daeschel. 1992. Influence of fat and emulsifiers on the efficacy of nisin in inhibiting Listeria monocytogenes in fluid milk. J. Dairy Sci. 75:387-393.

Kaushik, J. K., and R. Bhat. 2003. Why is trehalose an exceptional protein stabilizer? An analysis of the thermal stability of proteins in the presence of the compatible osmolyte trehalose. J. Biol. Chem. 278:26458-26465.

Kumpabooth, K., J. F. Scamehorn, S. Osuwan, and J. H. Harwell. 1999. Surfactant recovery from water using foam fractionation: Effect of temperature and added salt. Sep. Sci. Technol. 34:157-172.

Li, X., R. Shaw, and P. Stevenson. 2010. Effect of humidity on dynamic foam stability. Int. J. Miner. Process. 94:14-19.

Liu, W., and J. N. Hansen. 1990. Some chemical and physical properties of nisin, a small-protein antibiotic produced by Lactococcus lactis. Appl. Environ. Microbiol. 56:2551-2558.

Liu, W., H. Zheng, Z. Wu, and Y. Wang. 2010. Effects of pH profiles on nisin fermentation coupling with foam separation. Appl. Microbiol. Biotechnol. 85:1401-1407.

Liu, Z., Z. Liu, D. Wang, F. Ding, and N. Yuan. 1998. On the denaturation of enzymes in the process of foam fractionation. Bioseparation $7: 167-174$

Parente, E., and A. Ricciardi. 1999. Production, recovery and purification of bacteriocins from lactic acid bacteria. Appl. Microbiol. Biotechnol. 52:628-638.

Pilon, L., A. G. Fedorov, and R. Viskanta. 2002. Analysis of transient thickness of pneumatic foams. Chem. Eng. Sci. 57:977-990.

Pradhan, M. S., D. S. H. Sita Ram Sarma, and K. C. Khilar. 1990. Stability of aqueous foams with polymer additives: II. Effects of temperature. J. Colloid Interface Sci. 139:519-526.

Qu, Y.-H., G.-M. Zeng, J.-H. Huang, K. Xu, Y.-Y. Fang, X. Li, and H.-L. Liu. 2008. Recovery percentage of surfactant SDS and $\mathrm{Cd}^{2+}$ from permeate in MEUF using a continuous foam fractionators. J. Hazard. Mater. 155:32-38.

Roberts, R. F., E. A. Zottola, and L. L. Mckay. 1992. Use of a nisinproducing starter culture suitable for Cheddar cheese manufacture. J. Dairy Sci. 75:2353-2363.

Sarachat, T., O. Pornsunthorntawee, S. Chavadej, and R. Rujiravanit. 2010. Purification and concentration of a rhamnolipid biosurfactant produced by Pseudomonas aeruginosa SP4 using foam fractionation. Bioresour. Technol. 101:324-330.

Trmčić, A., C. Monnet, I. Rogelj, and B. B. Matijašić. 2011. Expression of nisin genes in cheese - A quantitative real-time polymerase chain reaction approach. J. Dairy Sci. 94:77-85.

Vanhoute, M., R. Froidevaux, C. Pierlot, F. Krier, J. M. Aubry, and D. Guillochon. 2008. Advancement of foam separation of bioactive peptides using an aeration column with a bubbling-draining method. Separ. Purif. Technol. 63:460-465.

Van't Hul, J. S., and W. R. Gibbons. 1996. Concentration and recovery percentage of the bacteriocin nisin from Lactococcus lactis. Biotechnol. Appl. Biochem. 24:251-256. 
Wu, Z., L. Wang, Y. Jing, X. Li, and Y. Zhao. 2009. Variable volume fed-batch fermentation for nisin production by Lactococcus lactis subsp. lactis W28. Appl. Biochem. Biotechnol. 152:372-382.

Yan, J., Z. Wu, Y. Zhao, and C. Jiang. 2011. Separation of tea saponin by two-stage foam fractionation. Separ. Purif. Technol. 80:300-305.

Yang, R., M. C. Johnson, and B. Ray. 1992. Novel method to extract large amounts of bacteriocins from lactic acid bacteria. Appl. Environ. Microbiol. 58:3355-3359.

Yoshii, H., F. Buche, N. Takeuchi, C. Terrol, M. Ohgawara, and T. Furuta. 2008. Effects of protein on retention of ADH enzyme activity encapsulated in trehalose matrices by spray drying. J. Food Eng. 87:34-39.
Yulin, X, Z. Weijiang, and Z. Hao. 2010. Synergetic decolorization and deodorization of sludge protein foaming solution by ${ }^{60} \mathrm{Co}$ $\gamma$-ray irradiation $/ \mathrm{H}_{2} \mathrm{O}_{2}$ oxidation. Process Saf. Environ. Protect. $88: 285-291$.

Zhang, F., Z. Wu, Z. Wu, and H. Wang. 2011. Effect of ionic strength on the foam separation of nisin from the fermentation broth. Separ. Purif. Technol. 78:42-48.

Zhang, S., Q. Lan, Q. Liu, J. Xu, and D. Sun. 2008. Aqueous foams stabilized by Laponite and CTAB. Colloids Surfaces A 317:406413 . 